\title{
Energy Indicators for Sustainable Development of Azerbaijan Republic - Economic Dimension
}

\author{
Sulduz Salimov ${ }^{1}$
}

\begin{abstract}
Starting with the publication of the Brundtland Report "Our Common Future" in 1987, various international and national organizations are developing sets of indicators for measuring and assessing aspects of sustainable development. When developing a national strategy for sustainable development, one should keep in mind the energy indicators of the sustainable development of the country prepared within the UN framework. Real assessment of the level of economic development of Azerbaijan Republic is impossible without the choice of a set of objective energy indicators that allow carrying out diagnostics of the state of the country's economy. In the article the author considers economic dimension energy indicators for sustainable development of Azerbaijan Republic on the basis of the UN methodology.
\end{abstract}

Keywords: energy indicator for sustainable development, sustainable development, oil and natural gas production, Azerbaijan economy, alternative energy resources, equator principles, economic dimension, industrial energy intensities, agricultural energy intensities, household energy intensities, transport energy intensities

\section{Introduction}

'Sustainable development' has been defined best by the Brundtland Commission as 'development that meets the needs of the present without compromising the ability of future generations to meet their own needs'[1]. Adequate and affordable energy supplies have been key to economic development and the transition from subsistence agricultural economies to modern industrial and service-oriented society's sustainable development of Azerbaijan Republic. Energy is central to improved social and economic well-being, and is indispensable to most industrial and commercial wealth generation. It is key for relieving poverty, improving human welfare and raising living standards. But however essential it may be for development, energy is only a means to an end [2].

Since the publication of the Brundtland Report (Our Common Future) in 1987, various international and national organizations are developing sets of indicators to measure and evaluate one or more aspects of sustainable development. After the adoption of the "Agenda for the 21st Century" action plan at the World Summit in 2012 ("Rio+20"), these achievements were approved at the highest level. In 2012, at the United Nations Conference on Sustainable Development the attending members reaffirmed their commitment to Agenda 21 in their outcome document called "The Future We Want". 180 leaders from nations participated. The 40th chapter of this action plan specifically states that countries and international governmental and non-governmental organizations developed a concept of sustainable development indicators and

PhD, senior research fellow at the Institute of Economy of National Academy of Sciences, Baku, Azerbaijan 
coordinated them at national, regional and global levels [3].

On September 25th 2015, countries adopted a set of goals to end poverty, protect the word and ensure prosperity for all as part of a new sustainable development agenda. The Sustainable Development Goals (SDG) are a collection of 17 interrelated global goals set out by the UN. Each of the broad goals has several targets. The total number of targets is 169. The SDG cover a broad range of social development issues, such as poverty, hunger, health, education, climate change, gender equality, water, sanitation, energy, environment and social justice. The SDG are also known as "Transforming our World: the 2030 Agenda for Sustainable Development" or Agenda 2030 in short.

\section{The United Nations (UN) Effort on Indicators of Sustainable Development}

In response to decisions taken by the United Nations (UN) Commission on Sustainable Development (CSD) and to Chapter 40 of Agenda 21, in 1995, the UN Department of Economic and Social Affairs (UNDESA) began working to produce a set of indicators for sustainable development. In the beginning, indicators addressed four main aspects of sustainable development: social, economic, environmental and organizational.

After testing at the national level, the Expert Group on Indicators of Sustainable Development (ISD) changed the management format. This was done to improve and facilitate the selection of policy decisions and the measurement of performance at the national level. The revised structure also refers to future risks, correlations between topics, sustainability goals and basic social needs. At one point, the UN ISD package included more than 130 indicators. The last version of the package includes 58 indicators classified into four dimensions (social, economic, environmental and organizational), 15 themes and 38 sub-themes. The number of indicators was greatly restricted when it became apparent that a large set of indicators was unwieldy and difficult to use effectively [3].

\section{Energy Indicators and Sustainable Development: The Commission on Sustainable Development and the Johannesburg Plan of Implementation}

The initial work on energy indicators was undertaken by the International Atomic Energy Agency (IAEA) in cooperation with the UN Division for Economic and Social Affairs (UNDESA) and other international and national organizations at the 9th session of the Commission on Sustainable Development (CSD- 9) in 2001 under the name of "Indicators for Sustainable Energy Development" (ISED). During this session, energy was a major theme. Increasing the availability of modern energy services for the poor part of the rural and urban population, as well as stimulating the economical use of energy resources by the rich, were among the most pressing issues identified in CSD-9. The dissemination of information on clean and efficient technologies, good practices and adequate policies was recognized as an important contribution to energy supply for sustainable development. The decisions taken by CSD-9 were suitable for the processing of EISD, including identification of key energy availability problems, energy efficiency, renewable energy, development of fossil fuel technology, nuclear energy technology, 
agricultural and transport energy.

Energy issues were discussed in the next year at the World Summit on Sustainable Development (WSSD), held in Johannesburg. The international community was based on the decisions taken by CSD-9, and again confirmed that affordable energy is an important goal of the millennium development, in order to halve by 2016 the number of people living in poverty. In the context of a large national policy, the WSSD agreed to facilitate access to reliable and cheap energy for poor people to stimulate sustainable development.

The Summit also called for changing unsustainable patterns of energy production and consumption. The Johannesburg Plan of Implementation (JPOI) that came out of the Summit urges all nations, groups and institutions to take immediate action to achieve the goals of sustainable development, the core set of energy indicators, now called Energy Indicators for Sustainable Development (EISD), has been designed to provide information on current energy related trends in a format that aids decision making at the national level in order to help countries assess effective energy policies for action on sustainable development[10]. In 2012, the United Nations Conference on Sustainable Development was also held in Rio, and is also commonly called Rio+20 or Rio Earth Summit 2012.

Indicators should facilitate understanding of what programs are necessary for sustainable development. They also need to determine which energy statistics should be selected and also determine the necessary capabilities of regional and national databases.

\section{Energy Indicator Efforts in Participating Agencies}

This communication is the result of an interagency effort led by the IAEA in cooperation with UNDESA, the IEA, the Statistical Office of the European Communities (Eurostat) and the European Environment Agency (EEA). This is a joint effort designed to eliminate duplication and provide users with a single set of energy indicators applicable in each country. In addition to interdepartmental joint work on EISD, each of these agencies has permanent energy programs or energy and environmental indicators, which are somewhat interrelated. These programs are designed to monitor and assess the trends of sustainable development in the respective Member States and regions. This activity complements the joint efforts for sustainable development.

The basic set of energy indicators for sustainable development (EISD), in conjunction with the structure used by the United Nations Commission on Sustainable Development (CSD), is classified in three aspects (social, economic and environmental). Some indicators can be classified in more than one aspect, topic, or sub-theme. In addition, each indicator can represent a group of related indicators that are necessary to assess a specific problem [2].

\section{Energy indicators for sustainable development of the economic dimension}

Modern economic systems depend on a reliable and adequate supply of energy, and developing countries should provide this as an indispensable condition for 
industrialization. All sectors of the economy - industrial, commercial, transport, service and agriculture - require modern energy services. These services, in turn, contribute to economic and social development at the local level, raising productivity, and generate income for the local population. The supply of energy affects employment, productivity and development. Electricity is the main form of energy for communications, information technology, production of goods and services. Energy consumption per unit of GDP is the total energy capacity. However, it is worth paying attention to the interpretation of this indicator. A country whose economy is based on banking and trade will use less energy per unit of GDP than the country whose economy is based on steel production and ore processing. Taking into account the structure of the economy, with the help of these indicators it is possible to monitor changes in energy efficiency, which in turn may be associated with changes in technology, fuel mix or consumer preferences and behavior.

There are indicators for assessing the intensity of energy in individual sectors, since they can be points of reference for energy efficiency, economic structure. However, the changes measured by the added value are subject to world commodity prices and currency fluctuations in the trade-dependent sectors, which can change the indicators significantly, but have nothing to do with actual changes in efficiency. Therefore, such indicators should be interpreted cautiously.

Effective energy assessment is the basis for effective energy supply and consumption and for effective reduction of pollution. Energy prices and related subsidies and taxes can support energy efficiency, improve accessibility, or can lead to inefficiencies in supply, supply, and energy consumption. While relatively high prices for commercial fuels may seem like a barrier to access, prices that cover the cost of supply are necessary in order to attract investment in a safe and reliable supply of energy.

Ensuring energy security is one of the main goals in the criteria of sustainable development of many countries. Interruptions in the supply of energy can cause serious financial and economic losses. To support the goals of sustainable development, energy must be available at all times, in sufficient quantities and at affordable prices. Safe energy supplies lead to the support of economic activity and to the provision of reliable energy services in society. Monitoring trends in net energy imports and the suitability of the relevant raw materials of the necessary fuel is important in order to assess energy security.

The development of energy indicators for sustainable development is far from complete, but projects of indicators for systems of different scales have already been proposed: global, regional, national, local, sectoral, and also for individual enterprises. While all these developments are preliminary. At the same time, on the one hand, new private and special indicators are proposed, so that the number of their species is continuously growing; on the other hand, attempts are made to search for integral indicators and even a single indicator.

The indicators proposed in the project require special transformations, adaptation to specific conditions, and in some cases - adjustments and extensions. The international economic indicators considered in the draft include indicators that characterize human activity, processes and characteristics that affect sustainable development; indicators of the state, characterizing the current state of various aspects of sustainable development. 
Development of the project of energy indicators for sustainable development required clarification of terminology, search for quantitative expressions for indicators. The abundance of indicators proposed by the international project makes it difficult to use them in many countries due to the lack of necessary information and statistical data. The system of indicators of sustainable development is important, primarily as a mechanism to achieve its goals, it is the basis for forecasting the activities of enterprises and the country as a whole.

\subsection{Energy use per capita}

This indicator measures the level of energy consumption per capita and reflects the total intensity of energy consumption by society. The actual value of the indicator is affected by a variety of economic, social and geographical factors. Energy is a key factor in economic development and in providing life benefits that determine the quality of life. Although energy is a key condition for economic development, its production and use have led to the main threats to the environment-the depletion of resources and the creation of pollution. On the one hand, the long-term goal-development and prosperityrequires increased energy consumption and the use of environmentally safe energy sources. On the other hand, limited access to energy is a serious constraint in developing countries, where energy consumption per capita is less than $1 / 6$ of consumption in industrialized countries. As can be seen from Fig.1. total primary energy supply per capita in the country has a steady downward trend: from 3,17 toe/capita in 1990 to 1,49 toe/capita in 2015, or 2,12 times.

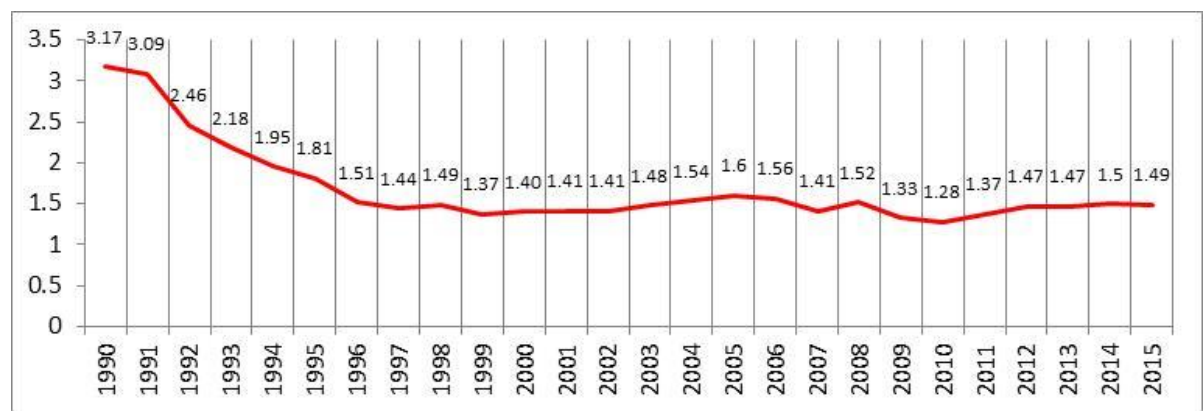

Fig.1 Total primary energy supply per capita in Azerbaijan in 1990-2015 years (toe/ capita)

For comparison (2015): The World 1,86; The European Union-28 -3,11; USA-6,80; China-2,17; Norway - 4,97; Russia-4,93; Kazakhstan-4,45; Turkmenistan-5,14; Turkey1,66; Iran-2,99 [14].

\subsection{Energy use per unit of GDP}

This indicator is calculated as the ratio of energy consumption to economic productivity. It reflects trends in total energy consumption relative to GDP, indicating the general relationship of energy consumption to economic development.

Energy is essential for economic and social development. However, the use of energy affects the availability of resources and the environment. In particular, the use of fossil fuels is the main cause of atmospheric pollution and climate change. Increasing energy 
efficiency is an important goal of sustainable development.

The ratio of total energy consumption to GDP is not an ideal indicator of energy efficiency, sustainability of energy consumption or technological development. The overall ratio depends on the energy intensity of the sectors, as well as on factors such as the type of climate, geography and the structure of the economy.

Comparison of the ratio of energy consumption to GDP by countries is complicated by geographical factors. Large countries, for example, have high levels of transportation of goods, there many goods are to be distributed nationwide. Compared to countries with a temperate climate, cold countries could consume significantly more energy per capita. Countries with a hot climate could use more energy per capita as a result of the need for air conditioning. Countries with economies that depend primarily on primary industries could use large amounts of energy per unit of manufacturing output compared to countries that import processed materials, due to the high intensity of energy use for processing raw materials. Canada, for example, has a high energy-to-GDP ratio because it is a large country with relatively cold weather and an economy that is highly dependent on raw materials for the manufacturing sector. In Japan, the climate is more moderate, raw materials are limited, and high population density leads to a lower ratio of energy consumption to GDP.

Interpretation of the relationship of energy consumption to GDP in terms of environmental impact, or sustainability, is also complicated by differences in the environmental impacts of different energy options. Canada, for example, has significant hydropower, nuclear energy and natural gas, which are sources of energy that have lower environmental impacts than coal or oil in terms of atmospheric pollution and climate change.

Given the large number of factors affecting energy consumption, the ratio of energy use to GDP should not be the only indicator of energy efficiency or survival in order to develop tactics.

As can be seen from Fig.2, total primary energy supply per unit of GDP in the country has a steady downward trend: from 1,02 toe / 1000 dollars USA in 1990 to 0,24 in 2015, or 4,25 times.

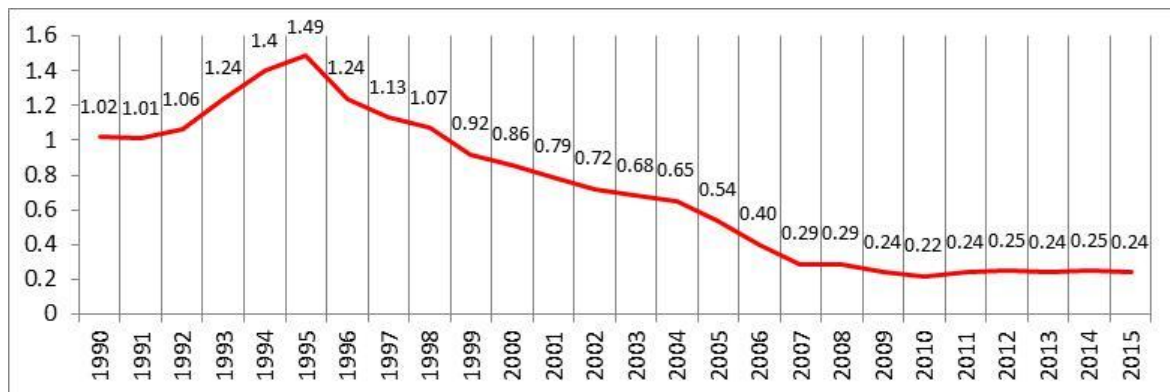

Fig.2 Total primary energy supply per unit of GDP in Azerbaijan in 1990-2015 years (toe/ thousand 2010 USD)

For comparison (2015): The World 0,23; The European Union-28 -0,14; USA-0,21; China-1,05; Norway - 0,08; Russia-0,58; Kazakhstan-0,76; Turkmenistan-1,28; Turkey0,14 ; Iran-0,34 [14]. 


\subsection{Efficiency of energy conversion and distribution}

The amount of energy produced, delivered and used can be obtained from the balance sheets of fuel and energy resources issued by individual countries or by various international or regional organizations.

This indicator measures the efficiency of conversion and energy distribution systems in various energy supply networks, including losses occurring during transmission and distribution of electricity and transportation and distribution of gas.

Improvement of energy supply systems leads to more efficient use of energy resources and to reduce negative environmental impacts. Efficiency of transmission and distribution of electricity is defined as the ratio of final electricity consumption to supply. Transmission and distribution of electricity are associated with losses in the transfer process from sources of supply to distribution points and distribution to consumers, including theft.

The efficiency of gas distribution is defined as the ratio of the final gas consumption to the gas supply. Losses during transportation and distribution of gas include losses during transportation between supply sources and distribution points, including gas consumed by gas pumping systems and during distribution to consumers.

The efficiency of oil refining is defined as the average percentage of output from incoming raw materials for processing. Both factors are expressed in terms of energy.

As can be seen from the curves in Fig.3, the share of energy losses in consumption is more than $4 \%$, which is a high value and significantly affects the state of the environment, primarily on the Absheron Peninsula [14]. Energy loss in 2007 increased by 884,6 thousand TOE and amounted to 1017,6 thousand TOE in 2016. Energy loss in 2007 increased by 884,6 thousand toe and amounted to 1017,6 thousand toe in 2016 $[10,15]$. Losses in total energy supply are high in Azerbaijan, which is $6.6 \%$ in 2016.

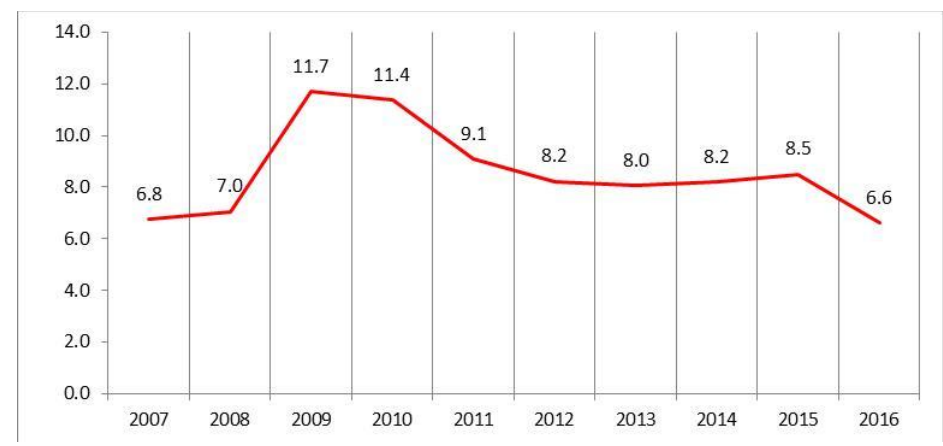

Fig.3 Losses shares of total energy supply in Azerbaijan in 2007-2016 years, percent

* has been compiled by author

\subsection{Industrial energy intensities}

Energy consumption is usually measured as the final energy at the point of consumption, i.e. in a factory or in an institution. The "own" energy must be combined with the energy purchased in order to obtain final energy consumption.

The industrial sector is the main energy consumer. This indicator measures the total energy consumption of the industry for the corresponding added value. The energy 
intensity gives information on the relative energy consumption per unit of output. This set of indicators can be used to assess trends in technological improvements and changes in the structure of the industrial sector and subsectors.

Increasing energy efficiency and reducing energy intensity in production processes are important goals for the sustainable development of countries around the world. Reducing energy intensity leads to more efficient use of energy and to a reduction in negative environmental impact.

Energy consumption per unit of added value is one of the ways to measure the energy demand for production.

While energy consumption per unit of physical production is the best indicator of energy efficiency in certain production processes, energy consumption per unit of economic output is also useful for linking energy efficiency to economic activity.

As can be seen from Fig. 4, the energy intensity in the industrial sector used of total energy supply of the republic has a clearly expressed growth trend, from 9,7\% in 2007 to $10,2 \%$ in $2016[10,15]$.

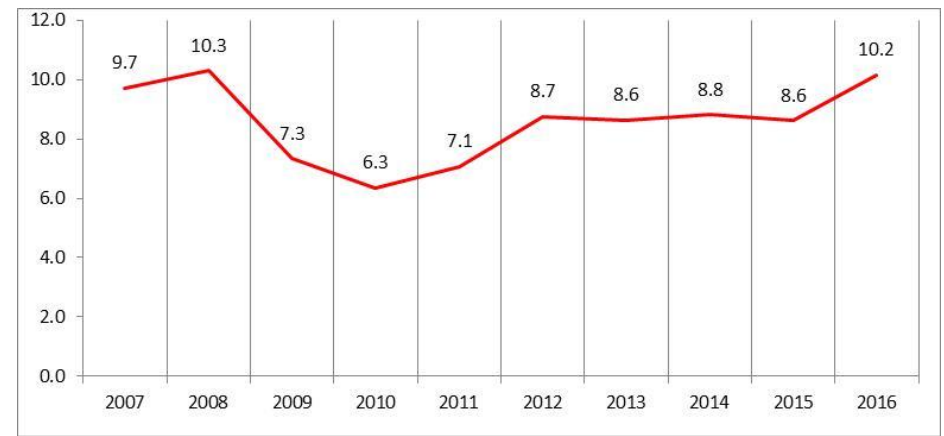

Fig.4 Industrial energy shares of total energy supply in Azerbaijan in 2007-2016 years, percent

* has been compiled by author

\subsection{Household energy intensities}

This indicator is intended to control the use of energy in the home sector. The home sector is the main user of energy with various uses. Increasing the useful energy activities in this sector is an important priority for many countries, as this leads to greater efficiency in the use of energy and a reduction in negative environmental impacts.

Home energy consumption encompasses the energy used in residential buildings, including urban and rural autonomous buildings. This energy use typically includes cooking, heating water, heating and cooling rooms, lighting, television and communications, computers, vacuum cleaners, etc. Home energy use should not include energy for farms, small businesses, the home sector should be separated from the service sector and the commercial sector. This should include not only commercial energy, but also non-commercial energy sources such as wood fuels and other biomass fuels.

As can be seen from Fig. 5, the energy intensity in the household of the republic has not changed, from $24,7 \%$ in 2007 to $24,8 \%$ in 2017 . In 2007 , the household energy intensities in total energy supply was 3236,5 thousand toe, up from 3816,6 thousand toe compared to 2016. For comparison, the natural population growth in the republic in 2007 increased from 8881,6 thousand person to 9706.6 thousand person in comparison with 2016 [10, 15]. 


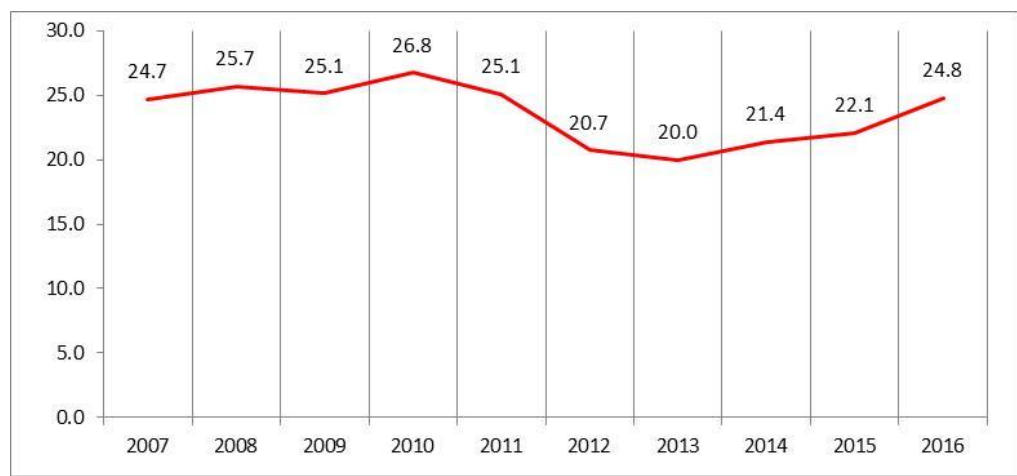

Fig. 5 Household energy shares of total energy supply in Azerbaijan in 2007-2016 years, percent

* has been compiled by author

\subsection{Fuel shares in energy and electricity}

This indicator determines the share of fuel for conversion to other types of energy (electricity and heat). In the economic aspect, the supply of different types of energy is the main factor of energy security. The optimal selection of different types of energy for a particular country relies on a diverse set of domestic and imported sources of fuel and energy. Concerning the ecological dimension, the type of energy supply has a major effect, since the environmental impacts of each energy source differ significantly and include the following:

$\checkmark$ traditional local or regional atmospheric pollution associated with the combustion of fossil fuels (e.g. city smog, acid rain);

$\checkmark$ global climate change associated with greenhouse gas emissions;

$\checkmark$ risks, typical for various fuel cycle networks.

The components of this indicator are consumption of various kinds of fossil fuels (coal, crude oil, oil products, gas); primary electricity and heat; renewable combustible waste.

As can be seen from Fig. 6, crude oil shares of total energy supply in Azerbaijan in was $61,3 \%$ in 2007, this indicator decreased by $40,5 \%$ in 2016 and natural gas shares of total energy supply in Azerbaijan in was 65,2\% in 2007, this indicator was 67,8\% in 2016.

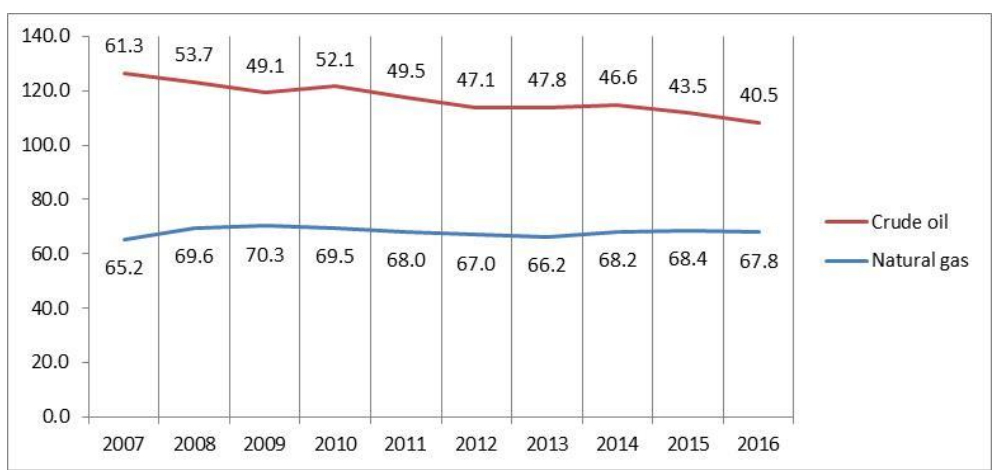

Fig.6 Crude oil and Natural gas shares of total energy supply in Azerbaijan in 2007-2016 years, percent

* has been compiled by author 


\subsection{Renewable energy share in energy and electricity}

This indicator measures the proportion of non-carbon energy sources in the generation of electricity. Receiving energy and electricity from non-carbon sources is a high priority for sustainable development for several reasons, from environmental protection to energy security and a variety of energy supply. An increase in the share of non-carbon fuels reduces the emission of greenhouse gases and other pollutants affecting local air quality and regional oxidation. The introduction of higher taxes for carbon energy sources leads to a higher proportion of non-carbon energy sources. This indicator is defined as the ratio of consumption and production of renewable energy to the total final supply and production of energy.

The share of renewable energy in the production of electricity is electricity produced using renewable energy, divided by the total use of electricity. This indicator measures the proportion of renewable energy in generating electricity.

Promoting the use of renewable energy sources is a high priority for sustainable development for several reasons, including safety and diversity of energy supply and environmental protection.

Renewable species include geothermal energy, solar, wind, hydro, and others. As can be seen from Fig.7, the share of non-carbon energy in total energy supply ranges from 2$3 \%$. This indicator is far below the EU and other developed countries. It should be noted that the EU plans to increase the share of renewable energy sources in the energy balance to $20-30 \%$ by 2030 .

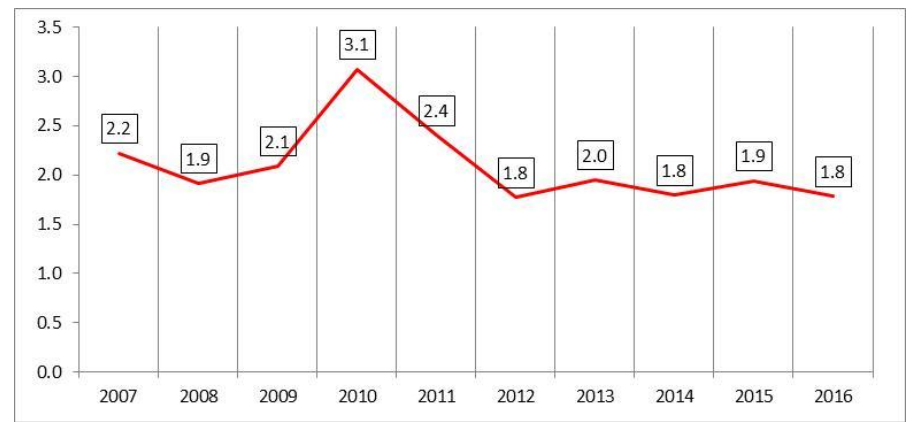

Fig.7 Renewable energy share in total energy supply in Azerbaijan in 2007-2016 years, percent

* has been compiled by author

Table 1: Energy balances in 2007-2016 years of Azerbaijan, thousand TOE.

\begin{tabular}{|c|c|c|c|c|c|c|c|c|c|c|}
\hline & 2007 & 2008 & 2009 & 2010 & 2011 & 2012 & 2013 & 2014 & 2015 & 2016 \\
\hline Tot & 13104,0 & 14495,4 & 13011,5 & 12566,5 & 13594,9 & 14390,0 & 14630,6 & 15085,5 & 15569,4 & 15393,5 \\
\hline Fin & 6534,2 & 7651,6 & 6524,5 & 6710,6 & 7291,8 & 7463,0 & 7765,6 & 8241,7 & 8304,3 & 644,9 \\
\hline$C_{t}$ & 034,1 & 7788,3 & 6392,4 & 6551,9 & 6728,0 & 6770,9 & 6992,0 & 7033,2 & 6768,8 & 6229,2 \\
\hline & 550,1 & 10089,9 & 9141,2 & \begin{tabular}{|l}
8734,9 \\
\end{tabular} & 9249,7 & 9639,5 & 9679,4 & 10294,3 & 10650,0 & 104 \\
\hline & 1273,5 & 1493,3 & 953,5 & 797,5 & 961,8 & 1258,9 & 1263,5 & 1329,2 & 1341,7 & 1563,5 \\
\hline & 1322,6 & 1642,3 & 1471,9 & 1704,4 & 1984,7 & 2180,8 & 2473,5 & 2559,4 & 2376,1 & 2220,7 \\
\hline & 3236,5 & 3722,9 & 3271,8 & 3362,1 & 3409,2 & 2981,9 & 2923,2 & 3226,3 & 3436,7 & 3816,6 \\
\hline & 291,3 & 277,5 & 272,0 & 386,6 & 326,7 & 255,0 & 285,4 & 271,1 & 302,3 & 274,3 \\
\hline 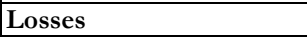 & 884,6 & 021,2 & 1520,9 & 1428,9 & 1235,9 & 1181,6 & 1177,4 & 1238,2 & 1325,0 & 1017,6 \\
\hline
\end{tabular}

Data Sources: SSCRA, EA, 2017, 2017. 
Table 2: Export of energy products balances in 2007-2016 years of Azerbaijan, thousand TOE.

\begin{tabular}{|c|c|c|c|c|c|c|c|c|c|c|}
\hline & 2007 & 2008 & 2009 & 2010 & 2011 & 2012 & 2013 & 2014 & 2015 & 2016 \\
\hline Crude oil & 35788,3 & 37926,9 & 45617,7 & 45798,6 & 40160,5 & 37822,4 & 37772,3 & 36248,9 & 36128,1 & 35986,6 \\
\hline Natural gas & 1695,9 & \begin{tabular}{|l|}
4892,1 \\
\end{tabular} & \begin{tabular}{|l|}
5456,3 \\
\end{tabular} & 5772,7 & 6360,6 & 6173,4 & 6818,4 & \begin{tabular}{|l|l|}
7551,0 \\
\end{tabular} & 7599,5 & \begin{tabular}{|l|l|}
7509,8 \\
\end{tabular} \\
\hline LPG & 52,3 & 112,5 & 126,0 & 176,6 & 123,9 & 102,0 & 104,8 & 39,8 & 17,6 & 66,6 \\
\hline Motor gasoline & 343,1 & 383,8 & 234,4 & 203,1 & 99,6 & 62,0 & 25,4 & 13,8 & 4,9 & 4,6 \\
\hline Kerosene - type jet & 324,6 & 212,9 & 280,1 & 118,2 & 81,3 & 150,5 & 135,4 & 202,8 & 243,8 & 243,6 \\
\hline Naphtha & - & - & - & 63,1 & - & - & - & - & - & - \\
\hline Diesel fuel & \begin{tabular}{|l|}
1434,2 \\
\end{tabular} & 1643,1 & 1607,4 & 1599,2 & \begin{tabular}{|l|}
1384,9 \\
\end{tabular} & 1160,7 & \begin{tabular}{|l|}
1105,4 \\
\end{tabular} & \begin{tabular}{|l|}
1552,1 \\
\end{tabular} & 1686,4 & 1251,4 \\
\hline Fuel oil - low sul & 940,2 & 591,2 & 35,0 & 187,1 & 216,3 & 108,7 & 231,7 & 240,4 & 115,1 & 23,8 \\
\hline Petroleum coke & 62,4 & 121,0 & 90,4 & 294,0 & 197,9 & 145,5 & 161,9 & 216,2 & 198,9 & 130,2 \\
\hline Bitumen & 28,0 & 28,2 & 13,2 & 13,7 & 19,6 & 10,9 & - & 3,1 & - & - \\
\hline Lubricants & 50,3 & 45,0 & 32,7 & 77,6 & 69,7 & 47,4 & 38,9 & 34,8 & 14,3 & 9,0 \\
\hline Other petroleum products & 14,5 & 10,3 & - & - & - & - & 25,4 & 24,1 & 24,1 & 1,9 \\
\hline Electricity & 67,6 & 69,8 & 32,6 & 39,8 & 69,2 & 58,5 & 42,6 & 42,1 & 22,8 & 94,2 \\
\hline
\end{tabular}

Data Sources: SSCRA, EA, 2017, 2017.

Table 3: Import of energy products balances in 2007-2016 years of Azerbaijan, thousand TOE.

\begin{tabular}{|l|c|c|c|c|c|c|c|c|c|c|}
\hline & $\mathbf{2 0 0 7}$ & $\mathbf{2 0 0 8}$ & $\mathbf{2 0 0 9}$ & $\mathbf{2 0 1 0}$ & $\mathbf{2 0 1 1}$ & $\mathbf{2 0 1 2}$ & $\mathbf{2 0 1 3}$ & $\mathbf{2 0 1 4}$ & $\mathbf{2 0 1 5}$ & $\mathbf{2 0 1 6}$ \\
\hline Crude oil & - & - & 1,0 & - & - & - & - & 0,1 & - & - \\
\hline Natural gas, million cubic metre & - & - & - & - & - & - & - & - & - & 278,4 \\
\hline Natural bitum and natural asphalt & 0,2 & 0,4 & 0,2 & 0,7 & 0,3 & 1,4 & 4,6 & 1,1 & 7,2 & 1,0 \\
\hline LPG & 0,1 & 0,1 & - & 0,1 & - & - & 0,1 & - & - & - \\
\hline Motor gasoline & - & - & 0,3 & 0,4 & 1,0 & 0,3 & 0,2 & 199,8 & 47,3 & 83,6 \\
\hline Diesel fuel & 11,3 & 40,0 & 8,4 & 0,1 & 0,1 & 3,2 & 2,0 & 0,9 & 12,6 & 4,0 \\
\hline Other kerosene & - & - & - & 0,5 & 0,3 & 20,1 & 29,2 & 4,6 & 14,9 & 10,9 \\
\hline Fuel oil - low sulphur & - & - & - & - & - & - & 9,6 & 21,2 & 137,0 & 189,5 \\
\hline Fuel oil - high sulphur & 39,3 & 4,1 & 1,4 & 0,2 & - & - & - & - & - & - \\
\hline Petroleum coke & - & 0,1 & - & 0,1 & 0,1 & - & - & 0,1 & 3,0 & 0,1 \\
\hline Bitumen & 0,3 & - & 3,0 & - & - & - & 20,0 & 0,1 & - & 4,7 \\
\hline Lubricants & 22,7 & 27,4 & 24,5 & 25,4 & 25,0 & 19,7 & 26,2 & 35,5 & 35,8 & 25,2 \\
\hline Other petroleum products & - & - & - & - & - & - & 33,8 & 19,1 & 32,4 & 16,1 \\
\hline Electricity & 47,1 & 18,5 & 9,4 & 8,6 & 11,0 & 12,1 & 11,0 & 10,7 & 9,3 & 9,8 \\
\hline Other fuel products & 10,8 & 12,0 & 9,3 & 7,4 & 7,5 & 8,9 & 9,2 & 6,4 & 8,6 & 5,4 \\
\hline
\end{tabular}

Data Sources: SSCRA, EA, 2017, 2017.

\section{Conclusions}

The analysis methodology of the UN Energy Indicators for Sustainable Development in Economic Dimension has shown that the system of indicators has been adopted for developed countries. The absence of a statistical basis makes it difficult to analyze some of the indicators of this methodology. Analysis of the indicators of this methodology shows that: Indicator Energy use per capita has sharply declined in comparison with 1990 to the fact that the production factory units of the Soviet Union were in the process of work. In the present situation, this indicator is closer to the World level than very low in developed countries. Comparisons show that indicator energy use per unit of $\boldsymbol{G D P}$ is the same as that of the world level, with lower developed countries (for example Norway), which is higher than in neighboring countries. Indicator Efficiency of energy conversion and distribution analysis revealed that the energy 
loss is high in the country and is 6-7\% of total energy supply. The analysis shows that indicator Industrial energy intensities is about $10 \%$ of total energy supplies and complement 1563.5 thousand toe. Indicator Household energy intensities is about $25 \%$ of total energy supplies and complement 3816.6 thousand toe. Indicator Fuel shares in energy and electricity are the basis for crude oil and natural gas for the Republic of Azerbaijan. Thus, crude oil is 40.5\% of total energy supplies and complement 6229.2 thousand toe and natural gas is $68 \%$ of total energy supplies and complement 10443.7 thousand toe. Indicator Renewable energy share in energy and electricity analysis showed that $1.8 \%$ of total energy supplies and complement 274.3 thousand toe. which is also a very low indicator for comparison.

The final analysis shows that it is important to investigate the methodology of the UN Energy Indicators for Sustainable Development in Azerbaijan. Investigating and analyzing these Indicators can give new impetus to the strategic development goals of the Republic of Azerbaijan.

\section{References}

WCED (World Commission on Environment and Development), 1987. Our Common Future. Oxford, UK: Oxford University Press.

Energy indicators for sustainable development: guidelines and methodologies. - Vienna: International Atomic Energy Agency, 2005.- 160 p.

UN Department of Economic and Social Affairs. "Areas of Work - National Information by Country or Organization". United Nations. Retrieved 15 August 2012.

Iris Borowy, Defining Sustainable Development: the World Commission on Environment and Development (Brundtland Commission), Milton Park: earthscan/Routledge, 2014.

IAEA/IEA, 2001. Indicators for Sustainable Energy Development, presented at the 9th Session of the CSD, New York, April2001. Vienna, Austria: International Atomic Energy Agency(IAEA)/International Energy Agency (IEA).

Indicators of Sustainable Development Framework and Methodologies. United Nations, 1996. — 428 p.

Salimov S.M., Mirzayev F.A., Shikhlinskaya R.Y., Sadiqova P.S. The concept of sustainable development indicators in the model analysis of fuzzy methods of Azerbaijan Republic// Вакu: Azerbaijan National Academy of Sciences Institute of Economy. Scientific works I Issue. - 2017. №1. P 6873.

Shikhlinskaya R.Y., Hajiyev N.J., Salimov S.M. A fuzzy model to assess e-government revenues// EGE Unversity Journal of the faculty of science Vol 39, NO2(2015) Bornova, Izmir Turkey: P. 1-10.

Salimov S.M., Maharrəmov A.M. Indicators of sustainable development strategy Azerbaijan Republic for the investigation of fuzzy methods// The 5th İnternational Conference on Control and Optimization with Industrial Applications, August, 2015, Baku, Azerbaijan: P.214-217.

Salimov S.M. Oil and gas industry is the basis of sustainable development strategy of the Republic of Azerbaijan // Moscow: MAKS Press, 2015. - 292 p.

Salimov S.M., Shikhlinskaya R.Y. Consideration of the possible rational use of non-renewable energy with neuro-fuzzy difficult way in the sustainable development strategy of Azerbaijan// Ваки: Azerbaijan National Academy of Sciences Institute of Economy. Scientific works IV Jssue. 2014. №4. P.318-321.

Salimov S.M., Maharromov A.M., Alizadeh E.K. Research methodology the United Nations energy indicators for sustainable development// Ваки: Azerbaijan National Academy of Sciences Institute of Economy. Scientific works III Jssue. - 2013. №3. S.299-303.

Salimov S.M. Consideration of the possible rational use of non-renewable energy with neuro-fuzzy difficult way in the sustainable development strategy of Azerbaijan // Ваки: Azerbaijan National Academy of Sciences Institute of Economy. Scientific works IV Jssue. - 2014. №4. P.318-321.

The Sustainable Development Goals Report- United Nations New York- 2016, - 54 p. 
Key World Energy Statistics 2017 - IEA: Paris, 2017- 97 p.

SSCRA, SYA, 2017. Statistical Yearbook of Azerbaijan 2017, State Statistical Committee of the Republic of Azerbaijan, Baku, Seda Press, 812 p.

SSCRA, IA, 2017. Industry of Azerbaijan. Statistical Yearbook, State Statistical Committee of the Republic of Azerbaijan, Baku, Seda Press, 344 p.

SSCRA, EA, 2017. Energy of Azerbaijan. Statistical Yearbook, State Statistical Committee of the Republic of Azerbaijan, Baku, Seda Press, 152 p.

Sustainable Energy for Development: German Development Cooperation in the Energy Sector - Bonifatius Druck, Paderborn, Germany, 2014. - 44 p.

Salimov S.M., Shikhlinskaya R.Y. Application of fuzzy logic for matching modes use of wind power plant with an electrical load schedule // ICAAM 2016. Third International Conference on Analysis and Applied Mathematics, The Abstract Book, 07-10. September. Almaty, Kazakhstan. P-256. 